\title{
Research on the Recipients' Reluctance to Go on with the Conversation in QQ Online Chatting
}

\author{
Jinjun Dai \\ Taizhou Radio \& Television University, Taizhou, China \\ Email: denisedaidai@foxmail.com
}

How to cite this paper: Dai, J.J. (2020) Research on the Recipients' Reluctance to Go on with the Conversation in QQ Online Chatting. Open Access Library Journal, 7: e6480.

https://doi.org/10.4236/oalib.1106480

Received: May 28, 2020

Accepted: June 14, 2020

Published: June 17, 2020

Copyright $\odot 2020$ by author(s) and Open Access Library Inc.

This work is licensed under the Creative Commons Attribution International License (CC BY 4.0).

http://creativecommons.org/licenses/by/4.0/

\section{(c) (i) Open Access}

\begin{abstract}
The purpose of the research is to find out what matters in maintaining online conversation between Chinese. QQ is a very popular online chatting tool among Chinese, but little research has been conducted examining how Chinese maintain their online conversations in this medium. Chinese conversation pays more attention to the fostering of the relationship, both in the F2F interaction and QQ online chatting. F2F interaction in Chinese everyday conversation is widely exploited as a strategic site for the analysis of the manner in which humans use verbal and non-verbal cues to maintain their interaction, especially in such areas as sentence-final particles and backchannels. The research selected two QQ conversations between two female interlocutors. Findings presented from descriptive analysis show that backchannels of "en" and "oh" receipts are important tools for alignment in QQ online chatting, and who initiates conversation matters in the conversation. Discussions are made in the comparison of the Chinese F2F interaction and QQ one-to-one online interaction.
\end{abstract}

\section{Subject Areas}

Online Social Network Computing

\section{Keywords}

F2F Interaction, QQ Online Chatting, SFPs, Backchannels

\section{Introduction}

Communication aims to foster or develop the relationship, whether it be in the form of F2F interaction or in the form of online. Along with F2F interaction, online chatting has received wide research attention in recent years. Some focus on chartrooms with multiparty participants [1]. And some focus on the one-to-one 
online chats [2].

QQ is a very popular online chatting tool among Chinese. It is free software that can be downloaded from www.qq.com. QQ user, when connected to Internet, can establish communications with his or her contacts by various means such as: voicemail, SMS or IM. QQ user has four statuses, namely: online, invisible, busy and offline. With the invisible status, his contacts may take him offline. When his contacts send him message at his invisible status, he may choose to respond or may choose to neglect by pretending to be offline at that particular moment. While at the online status, he usually could not be neglecting the message, otherwise he will be considered as rude. The messages could be stored as long time as ever, unless the QQ uses choose to delete them. But the records could be accessed both online and offline.

Chinese conversation bears its particular cultural characteristics. Chinese people are dominated by the value of Confucianism for thousands of years, which focuses on human relationship and permeates the ideal of "benevolence, harmony and formalized, ritualistic behavior" [3]. People attach great importance to the politeness so as to maintain friendly interpersonal relationship, reducing conflicts and misunderstanding. And in achieving the communicative aim, the Chinese conversation normally includes the components of pre-sequence, speech act, adjacency pairs, pre-closing and closing [4], which is also existent in the Chinese online conversations.

This paper sets out to compare the F2F interaction with the online chatting and to discover how the contacts maintain the relationship via QQ online chats. Especially, the paper, standing on the giants' shoulders, aims to unveil a discovery of the recipients' reluctance to go on with the conversation on the basis of one-to-one chat in QQ.

In meeting the needs of the data analysis, I structure my paper this way. In the part of the "previous research" below, I will go back to literature review of Chinese F2F conversation, especially the research on backchannels, sentence-final particles and some research of online chatting. In the "current study" part, my focus is on the analysis of the QQ online chatting data, in terms of the backchannels, sentences-final particles and so on. And finally come the discussion and conclusion.

\section{Literature Review}

As mentioned above, Chinese conversation is made up of pre-sequence, speech act, adjacency pairs, pre-closing and closing, or setting up, pragmatic act, uptake, pre-closing and closing. One of these components may be absent in some complete conversation according to the co-text [4]. However, each component helps to move the conversation forward by means of the backchannel, sentence-particles and so on.

Sentence-final particles (SFPs) have also been referred to as "modal particles", since they signal a speaker's attitude and/or sentiment s/he wishes to convey to- 
ward the addressee [5]. Chang [6] thinks that they are called "model particles" because they make the tone of sentence mild and moderate. Wong [7] considers the SFPS as "pragmatic devices", and illustrates that these pragmatic devices can help to reduce the illocutionary force in requesting by addressing the functional significance of the three Mandarin particles of ba, ya and ne. In the F2F interaction, Wong was convinced that they can be analyzed from the perspective of politeness and mitigation. They can be described as mitigators in a context where face threat is implicit.

Light [8] addresses, in particular, confirmation-seeking particles in connection with the use of high pitch, and notes that such particles are "the mark of intentional politeness and nonassertiveness, and higher donations indicate greater politeness and nonassertiveness."

Shih [9] mentions that women use a great deal of SFPs and interjections. She identifies such sentence-final particles as ma 嘛, ya 呀, ne 呢, la 啦, and ye 耶 as ones that are more frequently used by women. With respect to interjections, these include aiyo 哎聮 and aiya 哎呀.

As for backchanneling, it is that of the listener which functions to provide continuers or assessments, defining a listener's comprehension and/or interest. The listener uses the backchannels to steer the course, guide the direction of the talking and also suggest that they also have something to tell. In so doing, the backchannels are served to keep the alignment of the conversation.

Here is some research done by Chinese scholars on Chinese F2F interactions. Wuping [10] has classified backchannels in terms of forms, functions and positions. Considering forms, Chinese backchannels have statement label designator (e.g. “啊”), notional word (e.g. “对”) and repetition of the words of the previous interlocutor, and also the combined form of the above three, (e.g. " $m$ 对” is "statement label designator + notional word"). As far as the function is concerned, backchannels have three types of expressions as well, namely, those signaling the state of listening (e.g. “我听着呢”, means “I am listening”), signaling understanding (e.g. “我听明白了”, means “I understand”), signaling attitude (e.g. agree, disagree, query, surprise, etc.). Usually we determine their functions according to their co-text and the intonations used. As far as the position is concerned, there exist three categories. They may appear at the end of the intonation unit, in the middle or at the beginning.

Thus, F2F interactions in Chinese are abundant in research. The discourse of online chatting carries different names, such as "typed talk" [11] [12], Instant Messaging (IM) and Quasi synchronous computer-mediated communication (CMC) [2]. All these names partly display the differences between the F2F interaction and that of online.

Literatures concerning the comparison between the F2F interaction and online chatting are becoming ample. And conversation analysis is the tool to analyze the conversation. As CA is normally only used as the tool for the natural spoken conversation, there are some disputed views about whether CA would be 
applicable to the online conversation. But gradually, with the convincing examples and supports, many researchers cautiously take up the CA to illustrate the phenomena of the online chatting. Kupetz [13], for example, made her reflections on the applicability of the conversation analytic concepts to the description of the instant messaging on the basis of Skype chatting. She finds that these concepts like "turn-taking", "sequential organization" and "turn-constructional unit" are completely applicable to the online conversation.

The concept of backchannel in talk-in-interaction is also applicable to the online chatting, since these two types of talk share much in common. Beibwenger [14] said that with the irregularity of the turns in online chat, there is no chance for the recipient to influence the development of the communicative events through backchannels. But we have different stories.

\section{Current Study}

The study examined how back channeling in terms of 'evaluative utterances', e.g., "good", "romantic", "fabulous", and "oh" receipts mediate the alignment of online conversations on QQ in Mandarin between three Chinese friends. The focus of the conversational analysis was on: 1 . How does backchannel alignment keep the conversation going? 2. How do "en" and "oh" receipts and evaluative utterances operate as backchannels in the alignment in terms of the different speaker relationships? 3. Are "oh" receipts influential in the initiation of the conversation? 4. In what way the participant shows his or her reluctance to go on with the conversation?

In our current study, the data investigated came from the synchronous chat history of the friends over a period of one year. They chatted long before I asked for the records, therefore, they were naturally occurring conversations. The conversations chosen had different numbers of turns.

In the following example, the setting up is the two participants Denise and Lily who are the schoolmates, Lily being the senior. They are from the same city in China and were studying in the same university in Singapore when the conversation took place. Denise asks Lily some information about the air ticket to return to China.

In Chinese F2F interaction, we like to first give the background or reasons to get the listeners' sympathy, understanding and attention. This conforms to the Chinese pattern of thought which tends to be intuitive, concrete and rounded. It is called a way of climax. We start from the general to the concrete, from big to small, from far to near, from whole to part [4]. But in the QQ online chatting, usually we go directly into the exact topic at the very beginning.

1 Denise 14:04:02

你准备飞亚航吗

Are you going to take the Asia Airline?

2 Lily 14:04:13

恩, 
En,

3 Denise 14:11:11

恩。那你也准备这两天订票了, 是吧

En. So you are going to book the ticket as well these two days, right?

4 Lily 14:13:56

en

5 Denise 14:14:32

我们在珍珠坊的旅行社订的

We booked it in travel agency in Pearl Complex

6 Lily 14:14:50

o,

o,

*Notes: The number before the name of the interlocutor is the turn each person takes. The time after the name records exactly the hour they talk online.

In this fragment, the pragmatic act is performed by request. Denise made a request by using the interrogative SFP $m a$ at the end of the question. But Lily uses “恩” (en) receipt as the backchannel. “en” is similar to “Mm” in English.

Examining the characteristic uses of Mm in talk-in-interaction, Gardner [15] finds the three primary uses for marking recipiency are: as a weak acknowledger, as a continuer, and as a weak assessment token. It has been found that speakers of Mm systematically articulate the token with different prosodic shapes, namely, a falling, a fall-rising, and a rise-falling intonational contour, as different responses showing how they have received the antecedent utterance. They can be used as acknowledgments of problem-free receipt of the prior utterance with the falling contour, as continuer-like indices of a need for further talk from the other with the fall-rising contour, and as indices of problem-free receipt, but with an additional overlay of heightened involvement in the talk, such as surprise or sympathy, which makes them assessment-like objects with the rise-falling contour.

Different from the F2F interaction, QQ online chatting conversations lack access to the prosodic features and nonverbal information. Therefore, providing backchannels becomes more salient. Since online chatting conversations do not bear the different intonational contour of falling, rise-falling and fall-rising, the distinctions between different Mms are nonexistent. In online chatting, if oh or $\mathrm{Mm}$ receipts are said with a rising tone, it would be followed with a question mark.

In the example above, Denise initiates the conversation. And she continues with the conversation by a series of sequential organizations of "Question-Answer". She continues with several questions and looks forward to the answer. She starts with the first question "Are you going to take the Asia Airline?" and is responded by an “恩” (en). She then furthers the conversation by raising another question "So you are going to book the ticket as well these two days, right?" In particular, she uses the SFP ba. 
As for the SFP $b a$, Chan [5] finds that besides its use as a hedge in discourse, $b a$ has also been described as an SFP that is used to soften the tone of speech, making it less blunt, or less definite, in interrogatives and imperatives. And she also finds that the use of SFPs to soften an otherwise bare statement, question, or request can readily be seen as a politeness strategy that women might employ more than men, in response to prescribed social norms for women in Chinese culture.

Although with this politeness strategy, this question of Denise also is responded with an "en". After that Denise says "We booked it in travel agency in Pearl Complex" with the affirmative tone in the way of monologue. And Lily ends the conversation by a single "o". That is, at each of her speaking turn, the recipient chooses not to take the conversational floor. Rather, by means of the backchannel "en" or "o", Lily immediately cedes speakership back to Denise. From this line of analysis, we might say in using these backchannels, Lily lets the conversation become less robust and gradually go to a stop. If the conversation is compared to a river, the beginning is rather big, while the latter part of the river trickles down and later on dries.

One thing that needs to mention here is that of all the six turns in the above conversation, each of the contacts takes three turns. Of all Lily's three turns, she typed "en" and "o" in English in the last two turns. It is commonplace that nowadays among the Chinese intellectuals, they use a lot of code switching between English and Chinese. It is a significance here in using English rather than the Chinese word in this particular conversation. To Denise, it might suggest that, Lily is currently busy writing her English paper and not quite convenient to go on with the chat with Chinese language. Or she might be chatting with other people online at the same time in English, and she could hardly devote herself to both of the two conversations.

In the next example, conversation takes place between Dingding and Denise, who are colleagues. But when the conversation happened, Denise studied abroad, and Dinging invites Denise to attend her wedding ceremony.

21 Dingding 14:52:39

等你回来 估计我们已经住新房了 到时候欢迎来做客

When you are back, we may move to a new house. You are most welcome to visit.

(Denise was viewing the wedding pictures in her space.)

22 Denise 14:53:23

哦。新郎很帅啊。到时候我一定来。新房也在椒江吗

Oh. Bridegroom is handsome. I am sure to visit you then. Is your new house in Jiaojiang too? (Jiaojiang is the city where they work)

23 Dingding 14:53:37

是的

Yes

24 Dingding 14:53:43 


\section{在康平家园}

In Kangping Garden

25 Dingding 14:53:49

康平小区对面

Opposite Kangping Residential Area

26 Denise 14:54:09

哦, 动作还蛮快的哦。

$\mathrm{Oh}$, you are really quick.

27 Dingding 14:54:48

去年认识的

Got to know him last year

28 Dingding 14:54:57

呵呵 不过之前感觉不合适

Hehe but at first (I) didn't' think he's my type.

29 Dingding 14:55:05

很老实的一个孩子

A very honest kid

30 Dingding 14:55:20

不抽烟 不喝酒 也不怎么出去玩

Not drinking not smoking and hardly go out to relax.

31 Dingding 14:55:26

跟我性格差异很大

A very big contrast with my personality

32 Dingding 14:55:54

所以这次婚礼 我们拍了一个 $\mathrm{mv}$ 《一个像夏天, 一个像秋天》

So for this wedding, we have video taped an mv called "One's like a summer, one's like an autumn"

33 Denise 14:56:18

哦。好浪漫的

Oh. So romantic

34 Dingding 14:56:52

呵呵 先忙 等回头再给你汇报

Hehe take your time .I'll give you more detailed information shortly

35 Denise 14:57:39

好。再聊!

Ok. Catch you later!

In this fragment, Dingding initiates the conversation by asking Denise to attend her wedding and visit her new apartment. Denise responds by an "oh" receipts and an evaluative term, "Oh. Bridegroom is handsome." And at the same time, a question is raised to Dingding of "Is your new house in Jiaojiang too?" Dingding answers with three separate turns to this question. Then come Denise's another "oh" receipts and an evaluative term, "Oh, you are really quick." Then the speech act of communicating about her fiancé broken up into six sep- 
arate turns. It might have several possible reasons behind: 1. Dingding is waiting for the response from Denise, since Ding is not sure about the presence of Denise; That is, it is also common for online interlocutor to leave the computer for a moment while talking online 2. Dingding broke the speech into separate turns to show her excitement in communicating. 3. This is due to a lack of feedback or response. But this part of lack of feedback is understandable from Dingding's perspective, since she may think that Denise is still viewing her zone where her wedding pictures are put.

When Dingding is in a pretty good mood to talk, the other speaker Denise just uses some assessments to keep the conversation going. With the combination of the backchannels "oh" "en" and evaluative utterances, Denise takes the floor, but does not mean to further the talk. With this kind of backchannel, she actually means to relinquish and return the floor. What's significant here is that when one interlocutor always refuses to further the floor, the conversation will gradually become less lively and come to a stop. But compared with the first conversation, this one drags longer. The reason might be that "oh" receipts and "evaluative utterances" are better to encourage more conversations than the mere "o" or “en".

"hehe", the symbol of smiling, is used twice by Dingding. It can be interpreted as the friendly agreement to the previous turn in the first case and a predictor of the finishing of the conversation.

\section{Discussion}

Conversations involve extended turns during which one party is the teller and the other aligns as recipients. Active movement from one telling to another is something that two contacts should manage through work by which alignments shift from recipiency to speakership [16]. In both of the two conversations, however, the recipient of the conversation seldom tries to shift the role of recipient to that of speaker. "en" "oh" backchannels in online chat not only influence the development of the conversation, but a consecutive use of them by the recipient clearly shows that he or she is currently not quite available to be going on with the talk. He or she wants to end the conversation as soon as possible. But for the sake of politeness or relationship fostering, he or she drags by in the conversation by means of the "en" "oh" backchannels. People are the social human race. They gradually form behavioral and language conventions and blend into the society which is suitable to their own roles [4]. When chatting online, people also observe the chatting norms so as to well maintain the relationship between the contacts.

Interestingly, the contact Denise has been in both of the two conversations. She is the teller in the first data, and it is she who initiates the conversation. Being the recipient in the second example, Denise does not initiate the conversation. Instead, it is Dingding who takes the first move. Thus, it might be justifiable to say that it matters who initiates the conversation, since usually it is the re- 
cipient who uses short backchannels to show his or her reluctance in one-to-one online chatting.

One thing that needs to make clear here is that we do not take this straight use of "en" and "oh" as the rudeness of the recipient. We are just trying to observe the norm of the online chatting behavior.

\section{Conclusion and Future Perspectives}

This is an interesting area where we can find something psychological by peeping over the contacts' conversational behaviors. To our wonder, these behaviors could be mutually sensed by both of the two parties. On the one hand, both of them are trying their best to maintain the relationship. On the other hand, the recipients display their clues to show that they are currently not quite convenient to be sticking around to talk online. They must leave. But the recipients choose not to tell his or her contact in a direct way. Instead they appear to be elusive and evasive. But fortunately, this kind of massage has been caught by his or her contact. Thus, the conversation drops naturally.

With the narrow scope of the data, the research bears its limitations. All the contacts in the data are female. It might be a different case if one of the contacts in the conversation is male, or both of the contacts are male. This study, might, hopefully, lead to a much larger scale of research.

\section{Acknowledgements}

The author thanks the anonymous reviewers for their comments on this paper.

\section{Conflicts of Interest}

The author declares no conflicts of interest regarding the publication of this paper.

\section{References}

[1] Garcia, A.C. and Jacobs, J.B. (1999) The Eyes of the Beholder: Understanding the Turn-Taking System in Quasi-Synchronous Computer-Mediated Communication. Research on Language and Social Interaction, 32, 337-367. https://doi.org/10.1207/S15327973rls3204_2

[2] Kessler, F. (2008) Instant Messaging. Eine neue interpersonale Kommunikationsform. Net.worx 52, 1-72. http://www.mediensprache.net/networx/networx-52.pdf

[3] Scarborough, J. (1998) The Origin of Cultural Differences and Their Impact on Management. Westport, London.

[4] He, H.X. (2007) Pragmatic Acts in Chinese Conversation. Chinese Education Research Magazine of Innovation, 4, 5-8.

[5] Chan, M.K. (1997) Gender Differences in the Chinese Language: A Preliminary Report. Proceedings of the Ninth North American Conference on Chinese Linguistics, 2, 35-52.

[6] Chang, A. (1994) The Particle "NE": Function and Significance. Journal of Chinese Language Teachers' Association, 29, 89-92. 
[7] Wong, S.M.L (2010) Face Support-Chinese Particles as Mitigators. A Study of Ba A/Ya and Ne. Pragmatics, 8, 387-404. https://doi.org/10.1075/prag.8.3.01lee

[8] Light, T. (1982). On "Deing”. Computational Analyses of Asian and African Languages, 19, 21-49.

[9] Shih, Y.H. (1984) A Sociolinguistic Study of Gender Differences in Male and Female's Language in Chinese. Jiaoxue yu Yanjiu, 6, 207-229.

[10] 吴平. 汉语会话中的反馈信号[J]. 当代语言学, 2001,3(2): 119-126.

[11] Storrer, A. (2001) Getippte Gespräche oder dialogische Texte? Zur kommunikationstheoretischen Einordnung der ChatKommunikation. In: Lehr, A., Kammerer, M., et al., Eds., Sprache im Alltag. Beiträge zu neuen Perspektiven in der Linguistik. Herbert Ernst Wiegand zum 65. Geburtstag gewidmet, de Gruyter, Berlin, 439-465.

[12] Storrer, A. (2001) Sprachliche Besonderheiten getippter Gespräche: Sprecherwechsel und sprachliches Zeigen in der Chat-Kommunikation. In: Beißwenger, M., Ed., Chat-Kommunikation. Sprache, Interaktion, Sozialität \& Identität in synchroner computervermittelter Kommunikation. Perspektiven auf ein interdisziplinäres Forschungsfeld, Ibidem, Stuttgart, 3-24.

[13] Kupetz, M. (2009) Reflections on the Applicability of Conversation Analytic Concepts to the Description of Instant Messaging. Unpublished Term Paper, Communication in the New Media. Course Offered by Elizabeth Couper-Kuhlen. Department of English and American Studies, University of Potsdam, Potsdam.

[14] Beißwenger, M. (2007) Sprachhandlungskoordination in der ChaKommunikation. de Gruyter, Berlin. https://doi.org/10.1515/9783110953121

[15] Gardner, R. (1997) The Conversation Object Mm: A Weak and Variable Acknowledging Token. Research on Language \& Social Interaction, 30, 131-156. https://doi.org/10.1207/s15327973rlsi3002_2

[16] Zimmerman, D.H. (1993) Acknowledgment Tokens and Speakership Incipiency Revisited. Research on Language and Social Interaction, 26, 179-194. https://doi.org/10.1207/s15327973rlsi2602_4 